\title{
Creatine Prevents the Structural and Functional Damage to Mitochondria in Myogenic, Oxidatively Stressed C2C12 Cells and Restores Their Differentiation Capacity
}

\author{
Elena Barbieri, ${ }^{1,2}$ Michele Guescini, ${ }^{1}$ Cinzia Calcabrini, ${ }^{1,3}$ Luciana Vallorani, ${ }^{1}$ \\ Anna Rita Diaz, ${ }^{1}$ Carmela Fimognari, ${ }^{3}$ Barbara Canonico, ${ }^{1}$ Francesca Luchetti, ${ }^{1}$ \\ Stefano Papa, ${ }^{1}$ Michela Battistelli, ${ }^{1}$ Elisabetta Falcieri, ${ }^{1}$ Vanina Romanello, ${ }^{4}$ \\ Marco Sandri, ${ }^{2,4}$ Vilberto Stocchi, ${ }^{1}$ Caterina Ciacci, ${ }^{1}$ and Piero Sestili ${ }^{1}$ \\ ${ }^{1}$ Department of Biomolecular Sciences, University of Urbino Carlo Bo, 61029 Urbino, Italy \\ ${ }^{2}$ Interuniversity Institute of Myology (IIM), Urbino, Italy \\ ${ }^{3}$ Department for Life Quality Studies, Alma Mater Studiorum, University of Bologna, 47921 Rimini, Italy \\ ${ }^{4}$ Department of Biomedical Sciences, University of Padova, Venetian Institute of Molecular Medicine, 35129 Padova, Italy
}

Correspondence should be addressed to Piero Sestili; piero.sestili@uniurb.it

Received 22 January 2016; Accepted 29 June 2016

Academic Editor: Tiziana Persichini

Copyright (c) 2016 Elena Barbieri et al. This is an open access article distributed under the Creative Commons Attribution License, which permits unrestricted use, distribution, and reproduction in any medium, provided the original work is properly cited.

Creatine $(\mathrm{Cr})$ is a nutritional supplement promoting a number of health benefits. Indeed $\mathrm{Cr}$ has been shown to be beneficial in disease-induced muscle atrophy, improve rehabilitation, and afford mild antioxidant activity. The beneficial effects are likely to derive from pleiotropic interactions. In accord with this notion, we previously demonstrated that multiple pleiotropic effects, including preservation of mitochondrial damage, account for the capacity of $\mathrm{Cr}$ to prevent the differentiation arrest caused by oxidative stress in $\mathrm{C} 2 \mathrm{C} 12$ myoblasts. Given the importance of mitochondria in supporting the myogenic process, here we further explored the protective effects of $\mathrm{Cr}$ on the structure, function, and networking of these organelles in $\mathrm{C} 2 \mathrm{C} 12$ cells differentiating under oxidative stressing conditions; the effects on the energy sensor AMPK, on PGC-1 $\alpha$, which is involved in mitochondrial biogenesis and its downstream effector Tfam were also investigated. Our results indicate that damage to mitochondria is crucial in the differentiation imbalance caused by oxidative stress and that the $\mathrm{Cr}$-prevention of these injuries is invariably associated with the recovery of the normal myogenic capacity. We also found that $\mathrm{Cr}$ activates AMPK and induces an upregulation of $P G C-1 \alpha$ expression, two events which are likely to contribute to the protection of mitochondrial quality and function.

\section{Introduction}

Over the last few decades, the interest in creatine $(\mathrm{Cr})$ supplementation has increased notably. $\mathrm{Cr}$ has been used in different conditions, not only in improving skeletal muscle energy homeostasis [1-3] but also as a potential therapeutic agent for subjects suffering from muscle wasting and myopathies [4-8].

Cr supplementation has been shown to increase satellite cells and myonuclei number in human skeletal muscle, especially if associated with contractile activity [9-11]. The mechanisms by which $\mathrm{Cr}$ affects the growth and differentiation of myogenic cells are complex and probably not yet completely understood [12]. In 1972, Ingwall et al. [13] reported that $\mathrm{Cr}$ increases the expression of myosin heavy chain and induces muscle-specific protein synthesis in both skeletal and cardiac chicken myotubes in culture. Previous works by our group and others on $\mathrm{C} 2 \mathrm{C} 12$ myogenic cells have shown that $\mathrm{Cr}$ stimulates growth and protein accretion, associated with an increase in insulin-like growth factor 1 (IGF-1) mRNA and coordinated upregulation of myogenic regulatory factors mRNA $[14,15]$. In parallel with these positive effects in normal conditions, we also reported that pretreatment with $\mathrm{Cr}$, through multiple converging actions, prevents the inhibition of $\mathrm{C} 2 \mathrm{C} 12$ myoblasts' differentiation into mature myotubes caused by oxidative stress [15]. 
The oxidative-dependent actions on $\mathrm{C} 2 \mathrm{C} 12$ differentiating cells leading to a decrease of their cellular viability and to the myogenic arrest are complex $[15,16]$. Among other toxicological relevant events, we noticed severe ultrastructural damage to mitochondria suggesting that they could represent critical targets of oxidative attack and, interestingly, supplemental $\mathrm{Cr}$ was capable of preserving the integrity of mitochondrial ultrastructure [15]. In this regard, it is worth noting that $\mathrm{Cr}$ has been shown to protect mitochondria in other cell types exposed to various stressing conditions [17-19].

A growing body of evidence shows that mitochondria act as potential regulators of myogenesis and several studies suggest that impairment of mitochondrial structure and activity blocks myogenic differentiation. Indeed, mitochondrialtargeting chemicals, such as antimycin, azide, chloramphenicol, carbonyl cyanide, m-chlorophenylhydrazone carbonyl cyanide, p-(trifluoromethoxy)phenylhydrazone, ethidium bromide, myxothiazol, rotenone, and oligomycin tetracycline [20-30], inhibit the myogenic process. Moreover, it has been observed that respiration-deficient myoblasts lacking mitochondrial DNA-rho ${ }^{\circ}$ cells-fail to differentiate into myotubes $[22,23]$. Thus, the preservation of the mitochondrial integrity and functionality in differentiating myoblasts is necessary to complete the myogenic process in myotube maturation.

In the present study, we investigated the effect of $\mathrm{Cr}$ on oxidative-induced damage with a particular attention to mitochondrial ultrastructure, subcellular localization, and function in the early- $(24 \mathrm{~h}$ after serum removal, after exposure to $\mathrm{H}_{2} \mathrm{O}_{2}$ ) and middifferentiation phase (myotubes containing more than two nuclei, 48 or $72 \mathrm{~h}$ after serum removal) of myogenesis in $\mathrm{C} 2 \mathrm{C} 12$ cells.

Our findings provide insights into the mechanisms underlying the $\mathrm{Cr}$ protection of mitochondrial damage inflicted by $\mathrm{H}_{2} \mathrm{O}_{2}$ intoxication of $\mathrm{C} 2 \mathrm{C} 12$ cells and into the importance of this beneficial effect in preserving their myogenic capacity.

\section{Materials and Methods}

\subsection{Cell Culture and Treatment Conditions}

2.1.1. Cell Culture. C2C12 mouse myoblasts (Sigma-Aldrich, Italy) were cultured in DMEM (Sigma-Aldrich, Italy) supplemented with $10 \% \mathrm{v} / \mathrm{v}$ fetal bovine serum (Sigma-Aldrich, Italy), $2 \mathrm{mM}$ glutamine (Sigma-Aldrich, Italy), and antibiotics (50 U/mL penicillin, $50 \mu \mathrm{g} / \mathrm{mL}$ streptomycin, Sigma-Aldrich, Italy) for $24-48 \mathrm{~h}$ to reach $80 \%$ of cell confluence. $\mathrm{C} 2 \mathrm{C} 12$ cell differentiation was induced by serum withdrawal $1 \% \mathrm{v} / \mathrm{v}$ (Differentiating Medium, DM). Myogenic differentiation was performed as described in [15]. Cells were observed and processed for the experiments at critical time intervals, that is, at selected differentiation days (DifD), which are referred to in the text as "DifDn," where " $n$ " is the elapsed time, in days, from the commencement of differentiation.

2.1.2. Treatment Conditions. Cr preloading of $\mathrm{C} 2 \mathrm{C} 12$ was carried out by adding $3 \mathrm{mM}$ or $10 \mathrm{mM} \mathrm{Cr}$ (Creapure, AlzChem,
Germany) to myoblasts over the first $24 \mathrm{~h}$ of differentiation. At this time point (i.e., at the end of DifD1), Cr-supplemented or Cr-unsupplemented cultures were exposed to 0 or $0.3 \mathrm{mM}$ $\mathrm{H}_{2} \mathrm{O}_{2}$ for $1 \mathrm{~h}$ in serum-free medium and then cultured in Crand oxidant-free, DM up to day 3 (DifD3), when fusing cells were forming the first myotubes with more than two nuclei. Trolox (Sigma-Aldrich, Italy, $0.1 \mathrm{mM}$ ) was used as a positive control for the antioxidant effect as described in Sestili et al. [15]. Aminoimidazole-4-carboxamide ribonucleotide (AICAR, Sigma-Aldrich, Italy) was used ( $2 \mathrm{mM}$ for $1 \mathrm{~h}$ ) as a positive control for AMPK activation [31].

2.1.3. Estimation of Myogenic Index. The myogenic index was determined as reported elsewhere [32] and evaluated as the number of nuclei in myotubes divided by the total number of nuclei in myoblasts and myotubes. Twenty optical fields were randomly chosen.

2.1.4. Determination of Cell Viability. Cytotoxicity was determined using the trypan blue exclusion assay as described in Sestili et al. [15]. Results were expressed as per cent survival.

2.2. Analysis of Mitochondrial Properties. Mitochondria were analysed using in situ (permeabilized fixed and live cells) and in vitro (isolated mitochondria) approaches to study mitochondrial morphology, distribution, dynamics, and function under defined substrate conditions.

2.2.1. Mitochondrial Ultrastructure. For transmission electron microscopy (TEM) analysis, C2C12 monolayers were fixed with $2.5 \%$ glutaraldehyde in PBS for $5 \mathrm{~min}$, gently scraped, and centrifuged. Pellets were fixed again in a new fixative solution for $30 \mathrm{~min}$, $\mathrm{OsO}_{4}$ postfixed, alcoholdehydrated, and araldite embedded as reported in [33]. Thin sections were collected on nickel 300-mesh grids and stained with uranyl acetate and lead citrate. The observations were carried out with a Philips CM10 transmission electron microscope (FEI Company) at $80 \mathrm{KV}$.

\subsubsection{Live Cell Imaging Using Confocal Laser Scanning} Microscopy. For mitochondria and lysosome confocal live imaging, cells were grown on MatTek glass bottom chambers (MatTek Corporation, Ashland, MA) costained with $100 \mathrm{nM}$ MitoTracker red (MTR, Molecular Probes, Italy) and 500 nM LysoTracker green (LTG, Molecular Probes, Italy) and incubated for $30 \mathrm{~min}$ according to Luchetti et al. [34]. The incubation was performed at $37^{\circ} \mathrm{C}$ in $5 \% \mathrm{CO}_{2}$. Labelled mitochondria were observed by confocal microscopy on a Leica TCS SP5 II (Leica Microsystems, Italy) instrument and ImageJ software (NIH, Bethesda, MD).

Each sample was examined through successive optical slices $(0.2 \mathrm{~mm}$ each) along the $z$-axis, and the images obtained were postprocessed applying Wiener filter deconvolution. After deconvolution, the images were further processed in Image J software (NIH, Bethesda, MD) using the JACoP plug-in for colocalization studies. We used Pearson's coefficient as the parameter to measure colocalization in our samples. 
2.2.3. Mitochondrial Membrane Potential and Mass. Mitochondrial membrane potential $(\Delta \Psi)$ was quantified cytofluorimetrically according to Salucci et al. [35] by measuring the extent of uptake of the potentiometric dye, tetramethyl rhodamine methyl ester (TMRE, Sigma-Aldrich, Italy), normalized to MitoTracker Green (MTG), which is taken up by mitochondria independently of membrane potential. During the acute exposure to $\mathrm{H}_{2} \mathrm{O}_{2}$ at DifD1, myogenic C2C12 cells were stained with $100 \mathrm{nM}$ MTG for $30 \mathrm{~min}$ and in the last $15 \mathrm{~min}$ were coloaded with $50 \mathrm{nM}$ TMRE at $37^{\circ} \mathrm{C}$. Cells were observed immediately after the oxidative injury. To verify eventual hyperpolarization in case of mitochondrial dysfunction, cells were tested for their sensitivity versus oligomycin, a specific inhibitor of F0-part of $\mathrm{H}^{+}$ATP synthase, and samples were analysed with and without $5 \mu \mathrm{M}$ oligomycin (Sigma-Aldrich, Italy) for $1 \mathrm{~h}$, as described in Romanello et al. [36]. The protonophore carbonyl cyanide p-trifluoromethoxyphenylhydrazone (FCC, $4 \mathrm{mM}$ ) was then added to the cell culture medium. Fluorescent intensity in MTG was measured to estimate the overall mitochondrial mass.

\subsubsection{Analysis of Cardiolipin Content/Peroxidation. C2C12} cells were directly labelled in a well with $100 \mathrm{nM} 10-\mathrm{N}$-nonyl acridine orange (NAO), for $30 \mathrm{~min}$ at $37^{\circ} \mathrm{C}$ in $5 \% \mathrm{CO}_{2} . \mathrm{NAO}$ reflects total mitochondrial mass independently of activity because it binds to cardiolipin in the mitochondrial membrane. Following incubation, cells were harvested and $300 \mu \mathrm{L}$ of fresh medium was added. Changes in mitochondrial fluorescence intensity were analysed by FACScan flow cytometer equipped with CellQuest software (BD Biosciences, Italy) as described in [37].

2.2.5. Immunoblotting. Cells were lysed and immunoblotted as described earlier [15]. Blots were stripped using Restore Western Blotting Stripping Buffer (Amersham Pharmacia, Italy) and reprobed if necessary. The following primary antibodies from Cell Signaling were used: anti-AMPK, antiphospho-AMPK (Thr 172), anti-phospho-ACC (Ser 79), and anti- $\alpha$-tubulin (Sigma-Aldrich, Italy).

2.2.6. Mitochondrial Biogenesis. Cells cultured and treated as described above were analysed for the expression of specific mRNAs at DifD0, DifD1, DifD2, and DifD3. At each differentiation time, plates were washed with PBS; total DNA and RNA were extracted from cell cultures using QIAamp DNA and RNeasy Mini Kit (Qiagen, Germany), respectively, according to the manufacturer's instructions. All quantitative real-time PCR reactions were carried out in the StepOne Plus (Applied Biosystems, Italy) using 2x SYBR Select Master Mix (Life Technologies, Italy) and the PCR conditions were already described in Sestili et al. [15] and Barbieri et al. [33]. The relative gene expressions of peroxisome proliferatoractivated receptor gamma coactivator 1-alpha $(P G C-1 \alpha)$ and mitochondrial transcription factor A (Tfam) were quantified using $1 \mu \mathrm{L}$ of cDNA template; the amount of each target transcript was related to that of the gene encoding ribosomal protein $\mathrm{S} 16$. The $\mathrm{mtDNA} / \mathrm{nDNA}$ ratio was obtained as reported in Barbieri et al. [33], relating the mitochondrial and nuclear DNA quantities amplifying both COXII and GAPDH as mtDNA and nDNA targets, respectively. All oligonucleotide primers have been previously described in Barbieri et al. [33].

2.2.7. Mitochondrial Proteomic Analysis. Mitochondria from $3 \times 10^{7}$ cells were extracted as previously described [33] and suspended in $8 \mathrm{M}$ urea, 4\% CHAPS, $65 \mathrm{mM}$ DTE, and $40 \mathrm{mM}$ Tris base and sonicated for $5 \mathrm{~s}$ on ice. Following centrifugation at $21000 \mathrm{~g}$, protein concentration was determined by Bradford assay [38] and $80 \mu \mathrm{g}$ of total proteins used for 2-dimensional electrophoresis (2DE). Analytical gels were stained with silver nitrate [39], while semipreparative gels for mass spectrometry analysis were stained with Brilliant Blue R250 (Sigma-Aldrich, USA). Gel images were acquired by Fluor-S MAX multi-imaging system (Bio-Rad Laboratories Italy, Segrate, Italy), and the data were analysed with ImageMaster 2D Platinum software. Gel digestion was carried out according to Shevchenko's protocol [40] and LC-ESIMS/MS analysis was performed using a Q-TOF micro ${ }^{\mathrm{TM}}$ mass spectrometer (Micromass, UK) as previously described [41].

2.2.8. Statistical Analysis. Unless noted otherwise, the results were expressed as mean values \pm SD. The significance of differences between the mean values recorded for different experimental conditions was calculated by Student's $t$-test and $P$ values are indicated where appropriate in the figures and their legends.

With respect to the determination of $\Delta \Psi$, cardiolipin, AMPK, ACC, PGC-1a, and Tfam levels and mtDNA copy numbers, the effects of all treatments were tested using a twotailed one-way ANOVA analysis. Tukey's post hoc test was performed using GraphPad Prism version 5.00 for Windows (GraphPad Software, USA). The significance threshold was set to 0.05 .

\section{Results}

3.1. Effects of $\mathrm{Cr}$ on Mitochondrial Ultrastructure of $\mathrm{H}_{2} \mathrm{O}_{2}$ Treated C2C12 Cells. The effect of oxidant injury $(0.3 \mathrm{mM}$ $\mathrm{H}_{2} \mathrm{O}_{2}$ for $1 \mathrm{~h}$ ) on the viability and myogenic index of $\mathrm{C} 2 \mathrm{C} 12$ myoblasts with or without Cr supplementation (3 or $10 \mathrm{mM}$ for $24 \mathrm{~h}$ ) committed to differentiate was first determined. Oxidative challenge resulted in a reduction of cell survival $(67.3 \% \pm 5.324 \mathrm{~h}$ after intoxication $)$ and in severe inhibition of myogenic differentiation of surviving cells (with a myogenic index of $0.081 \pm 0.0072$ as compared to $0.51 \pm 0.047$ of controls): both events could be prevented by $3 \mathrm{mM} \mathrm{Cr}$ supplementation (survival of $93.3 \% \pm 8.4$ and a myogenic index of $0.45 \pm 0.039$ ). $10 \mathrm{mM} \mathrm{Cr}$ yielded results not significantly different as compared to $3 \mathrm{mM}$; therefore, the lower concentration was used in subsequent experiments.

The effects of supplemental $\mathrm{Cr}$ on the mitochondrial ultrastructural damage in this intoxication setting were then studied with TEM. Figure 1(a) shows TEM micrographs taken at DifD1, immediately after oxidative insult; $\mathrm{H}_{2} \mathrm{O}_{2}$ treatment induced severe ultrastructural damage to the majority of 


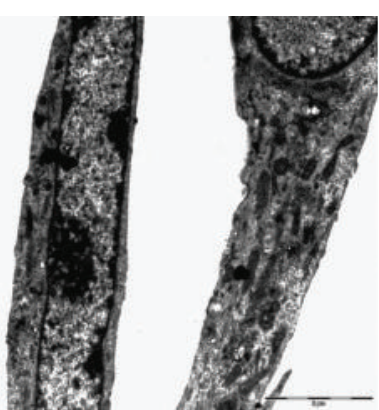

Control

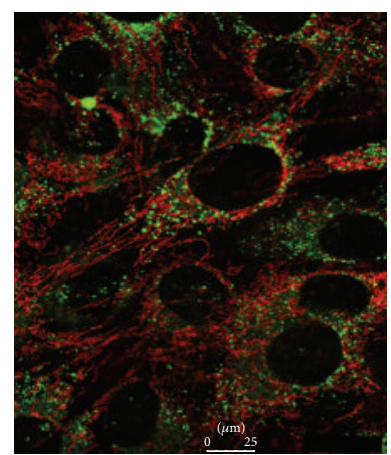

Control

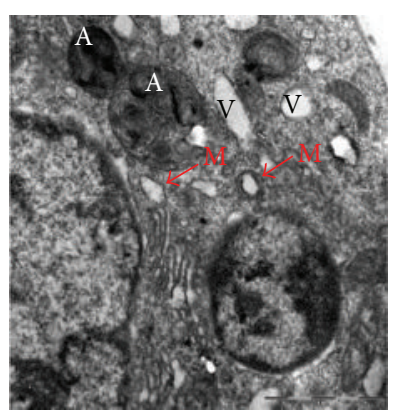

$\mathrm{H}_{2} \mathrm{O}_{2}$

(a)

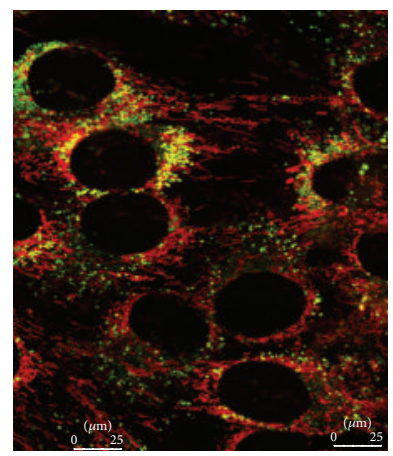

$\mathrm{H}_{2} \mathrm{O}_{2}$

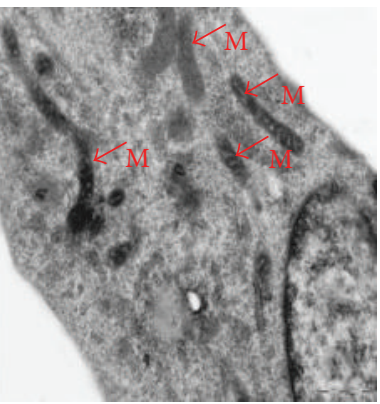

$\mathrm{H}_{2} \mathrm{O}_{2} / \mathrm{Cr}$

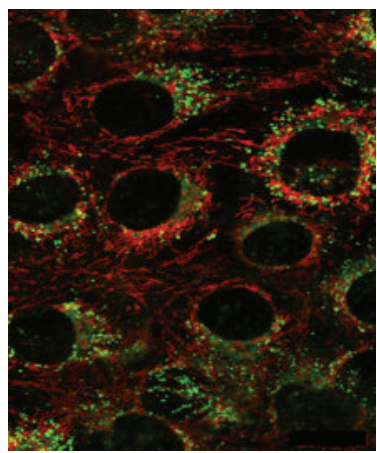

$\mathrm{H}_{2} \mathrm{O}_{2} / \mathrm{Cr}$

(b)

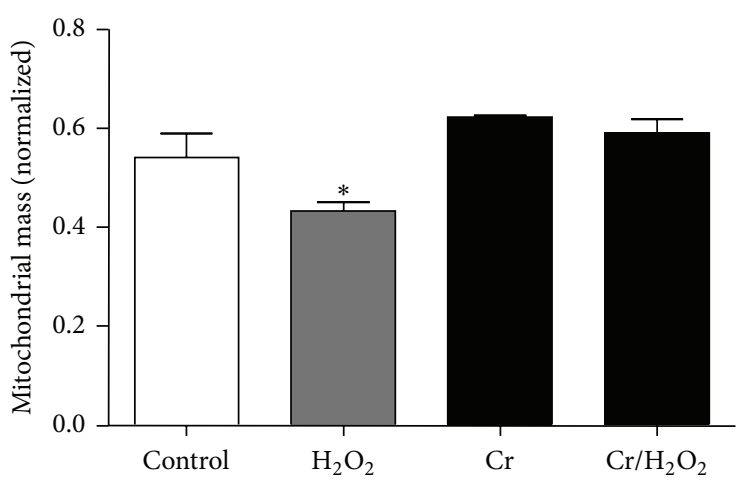

(c)

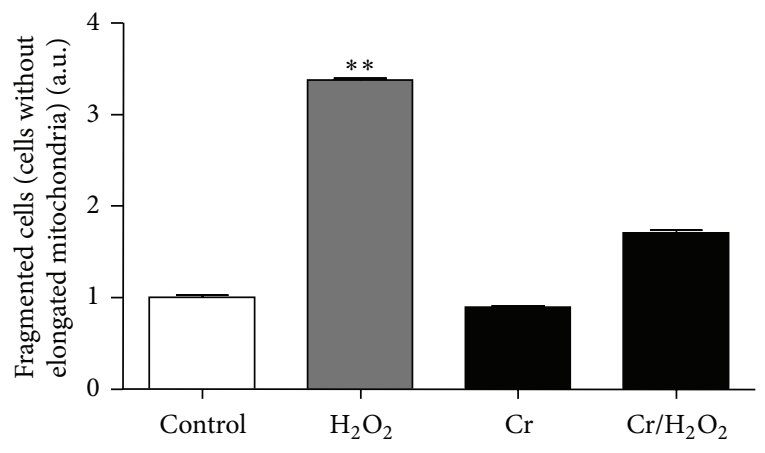

(d)

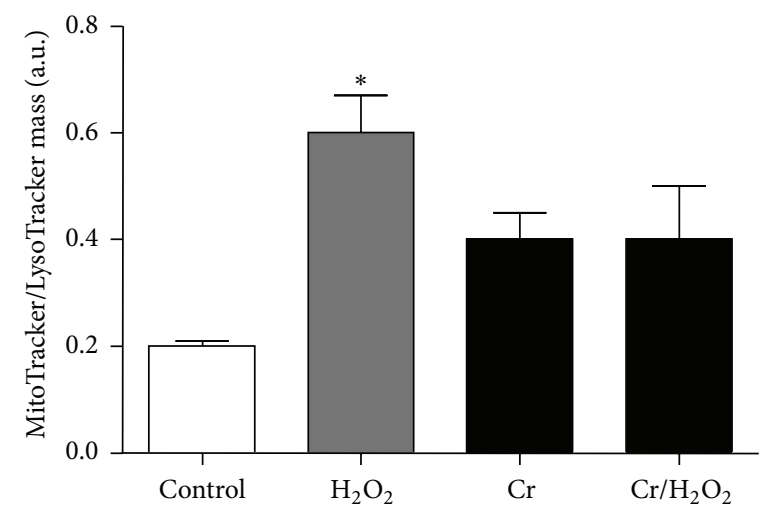

(e)

FIGURE 1: Protective effect of Cr on oxidant-injured mitochondria in differentiating C2C12 myoblasts. TEM micrographs and confocal images were taken immediately after oxidative stress at DifD1. Images were representative of five independent experiments. (a) $\mathrm{H}_{2} \mathrm{O}_{2}$ treatment induced cytoplasmic vacuolization, mitochondrial swelling, and disruption; Cr prevented the effect of $\mathrm{H}_{2} \mathrm{O}_{2}$ : Cr-supplemented cells appeared comparable to the controls, showing lower cytoplasmic vacuolization and numerous elongated mitochondria with perfectly preserved cristae. $\mathrm{Bar}=2,1$, and $0.5 \mu \mathrm{m}$ specified in each micrograph. V: vacuole; A: autophagosome; M: mitochondrion. (b) Confocal microscopy of C2C12 myoblasts after double staining with MitoTracker (MTR) and LysoTracker (LTG) showing the mitochondrial network morphology and lysosome distribution within myocytes and the effect of oxidative challenge with or without Cr supplementation. Bar $=25 \mu \mathrm{m}$. (c) Analysis of confocal images showing the quantification of mitochondrial mass. (d) Number of cells with fragmented mitochondria. (e) Extent of colocalization of MTR and LTG. Data are the means \pm SD. ${ }^{*} P \leq 0.05 ;{ }^{* *} P \leq 0.01$ compared to control $(n=5)$. 
the mitochondria, which showed typical matrix swelling and loss of cristae. Notably, Cr supplementation protected mitochondria from these injuries: their number was comparable to that of controls and they displayed an elongated shape and well-preserved cristae. We also observed distinctive $\mathrm{H}_{2} \mathrm{O}_{2}$ mediated cytoplasmic vacuolization, typical of myocytes' response to oxidative insult [15]. We likewise observed several autophagic vacuoles with double membranes containing disorganised mitochondrial cristae; sometimes, autophagic vacuoles occurred close to the sarcolemma. Again, Cr treatment prevented the formation of these cytoplasmic vacuoles.

Going back to viability and myogenic index, according to previous data [15], addition of Trolox (an established radical scavenger included as a positive control) resulted in a qualitatively and quantitatively different protective effect as compared to $\mathrm{Cr}$ against $\mathrm{H}_{2} \mathrm{O}_{2}$ challenge, in that it prevented $\mathrm{C} 2 \mathrm{C} 12$ cells' decrease in viability (cell survival of $91.2 \% \pm 6.4$ versus $67.3 \% \pm 5.3$ of $\mathrm{H}_{2} \mathrm{O}_{2}$-only-treated cells) but was unable to restore their differentiation capacity (a myogenic index of $0.20 \pm 0.019$ as compared to $0.45 \pm 0.039$ of $\mathrm{H}_{2} \mathrm{O}_{2}$-injured, Cr-supplemented cells and $0.51 \pm 0.047$ of controls).

3.2. Effect of $\mathrm{Cr}$ on Mitochondrial Morphology. Confocal images in Figure 1(b) show filamentous mitochondria with well-defined tubular shapes in control cells, while $\mathrm{H}_{2} \mathrm{O}_{2}$ treatment caused an increase in fragmented, round, and perinuclear-located mitochondria. Interestingly, Cr preloading prevented these morphological alterations; indeed, mitochondria maintained their filamentous and tubular shape paralleling the myocytes' elongation axis typical of controls. Cells preloaded with $\mathrm{Cr}$ per se present a mitochondrial profile identical to controls (not shown).

The analysis of the fluorescence intensity of high definition confocal images allowed us to quantitate mitochondrial mass at the early differentiation phase (immediately after $\mathrm{H}_{2} \mathrm{O}_{2}$ insult, DifD1, Figure 1(c)); results demonstrated a significant decrease of mitochondrial mass in oxidative damaged myocytes. By contrast, $\mathrm{Cr}$ preloading of $\mathrm{H}_{2} \mathrm{O}_{2}$ treated cells prevented this effect.

Further analysis (see Section 2.2.2) of the above images showed that, in comparison, $\mathrm{H}_{2} \mathrm{O}_{2}$ treatment led to a significant increase in the number of fragmented mitochondria with small perinuclear ring shapes. The cells showing $70 \%$ fragmented or intermediate mitochondria were classified as fragmented cells [42]; their number increased significantly upon infliction of oxidative treatment and, not surprisingly, Cr preloading prevented this effect (Figure 1(d)).

In these oxidative stressing conditions, lysosomes are likely to be actively involved in the removal of damaged mitochondria, as suggested by the appearance of autophagosomes revealed by TEM (Figure 1(a)). To strengthen this point, the degree of mitochondria sequestration by lysosomes was quantified by performing a double staining protocol with MTR and LTG, followed by quantification of the lysosomal and mitochondrial overlapping. This analysis showed that oxidative stress caused intense perinuclear colocalization of lysosomes with mitochondria (Figure 1(e)), a finding in

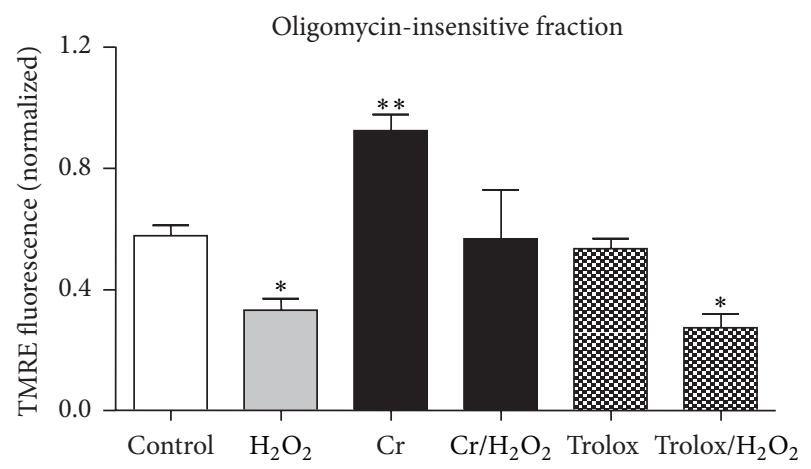

FIGURE 2: Protective effect of $\mathrm{Cr}$ on mitochondrial $\Delta \Psi$ after oxidative challenge in differentiating $\mathrm{C} 2 \mathrm{C} 12$ myoblasts. The mitochondrial $\Delta \Psi$ (normalized ratio TMRE/MTG) was evaluated immediately after oxidative stress (DifD1) as the mitochondrial fraction insensitive to oligomycin. Data are the means \pm SD. ${ }^{*} P \leq 0.05 ;{ }^{* *} P \leq 0.01$ compared to control $(n=5)$.

line with the ultrastructural TEM observations. Not surprisingly, $\mathrm{Cr}$ was found to consistently prevent the lysoso$\mathrm{mal} /$ mitochondrial colocalization and to preserve the diffuse localization of lysosomes within the cytoplasm. Notably, the established bona fide antioxidant Trolox showed a much weaker protective effect than $\mathrm{Cr}$ (not shown). Remarkably, in Cr-only-supplemented cells, well-preserved, mostly elongated mitochondria could be observed (not shown).

\subsection{Effect of $\mathrm{Cr}$ on Mitochondrial Membrane Potential.} Mitochondrial membrane potential per mitochondrial unit was studied cytofluorimetrically at DifD1 determining their TMRE/MTG ratio, which reflects the extent of $\Delta \Psi$, in the presence of oligomycin (5 $\mu \mathrm{M}$; see Section 2.2.3) [36]. In particular, our analysis (Figure 2) indicates a significant reduction of TMRE/MTG ratio (oligomycin-insensitive fraction) in oxidatively injured cells as compared to controls, an effect that could be prevented by $\mathrm{Cr}$ supplementation; Cr-only-treated myoblasts showed a significant increase in the TMRE/MTG ratio. Notably, Trolox, unlike Cr, failed to prevent the loss of $\Delta \Psi$ in oxidatively injured cells.

3.4. Effect of Cr on Cardiolipin Peroxidation. Flow cytometric analysis of $\mathrm{NAO} /$ cardiolipin interaction (a reliable marker of mitochondrial oxidative damage) showed that $\mathrm{H}_{2} \mathrm{O}_{2}$ treatment caused significant peroxidation of cardiolipin within $24 \mathrm{~h}$ after $\mathrm{H}_{2} \mathrm{O}_{2}$ challenge (Figure 3), an effect which could be significantly hampered by $\mathrm{Cr}$, which afforded a $32 \%$ protection rate; Trolox was slightly more effective in preventing cardiolipin peroxidation.

3.5. Effect of Cr on the Expression of AMPK. Figure 4(a) shows that $\mathrm{Cr}$ preloading increased the extent of phosphorylation of AMPK and of its downstream firmly established substrate acetyl-CoA carboxylase (ACC). $\mathrm{H}_{2} \mathrm{O}_{2}$ treatment, per se, also induced AMPK activation, in accordance with literature data [43]. Interestingly, in Cr-supplemented, oxidatively treated cells, the increase of AMPK phosphorylation was higher 


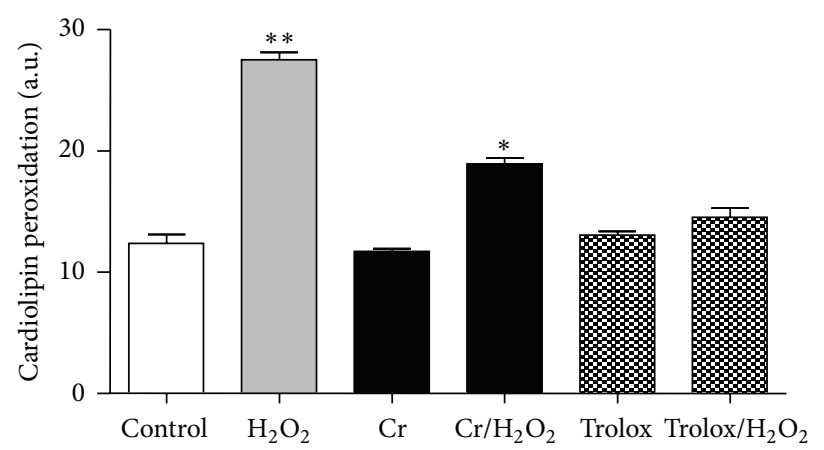

FIgURE 3: Protective effect of $\mathrm{Cr}$ on cardiolipin peroxidation induced by oxidative challenge in differentiating $\mathrm{C} 2 \mathrm{C} 12$ myoblasts. Flow cytometric analysis of the cardiolipin-sensitive probe 10-nonyl acridine orange (NAO) was used to monitor changes in mitochondrial lipid peroxidation in differentiating oxidatively challenged C2C12 cells pretreated with 0 or $3 \mathrm{mM}$ Cr. Analysis was performed at DifD2. Data are the means \pm SD. ${ }^{*} P \leq 0.05 ;{ }^{* *} P \leq 0.01$ compared to control $(n=5)$.

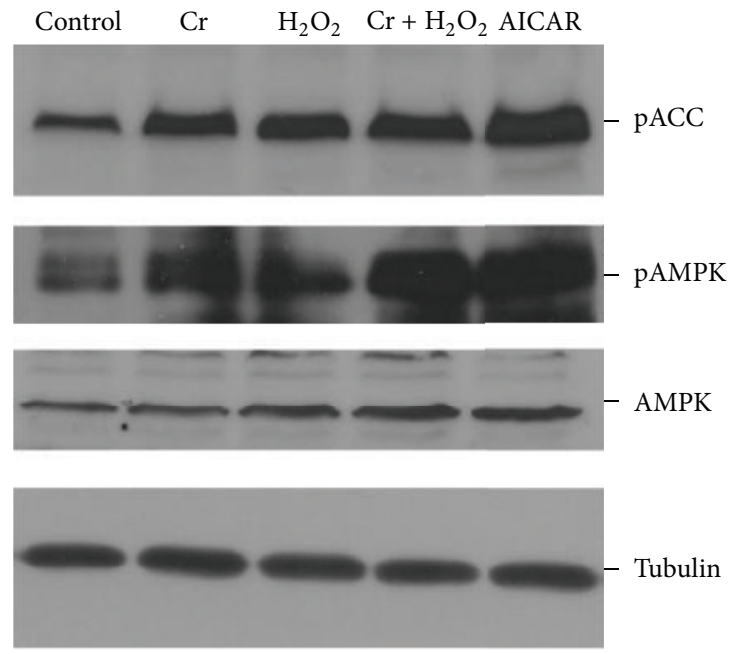

(a)

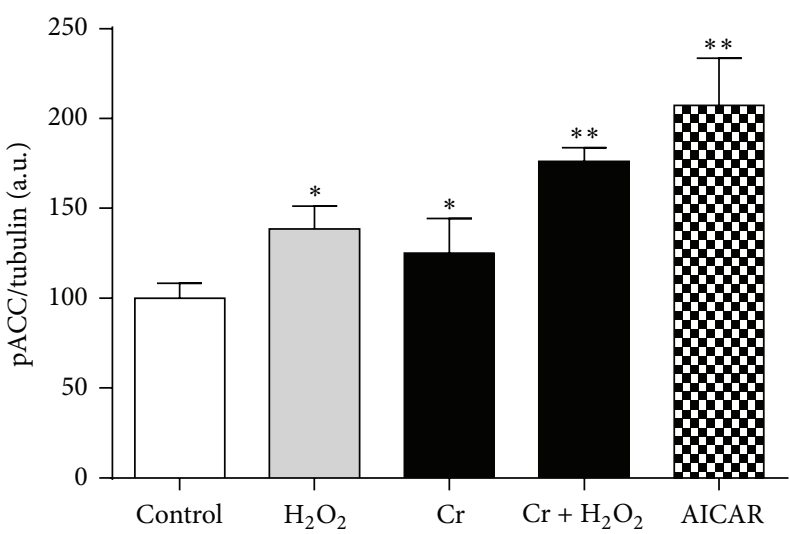

(b)

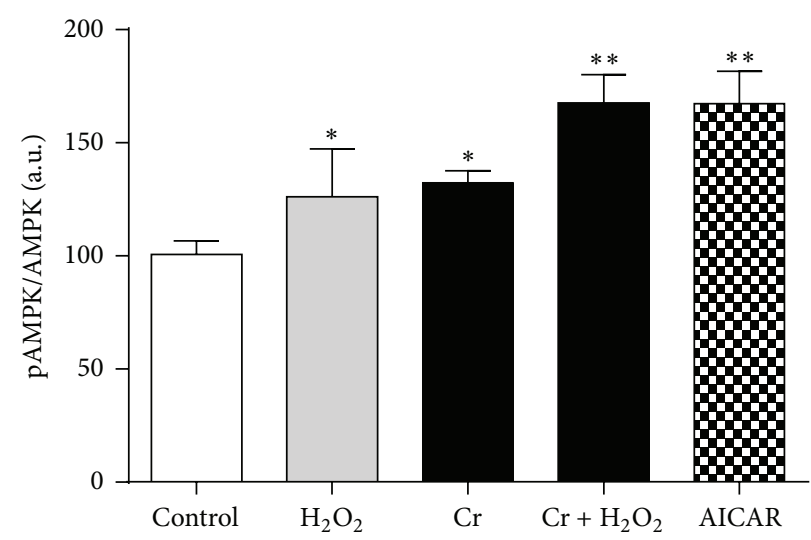

(c)

FIGURE 4: Effect of Cr on AMPK. (a) The cell lysates were separated by SDS-PAGE and analysed for pACC, pAMPK, and AMPK protein expression by Western blotting after the oxidative insult (DifD1); representative images were reported. Blots were also probed for tubulin protein as loading control. (b) The levels of phosphorylated AMPK versus total AMPK and (c) the levels of phosphorylated ACC versus tubulin were examined. Data are the mean \pm SEM. ${ }^{*} P \leq 0.05 ;{ }^{* *} P \leq 0.01$ compared to control $(n=4)$. 


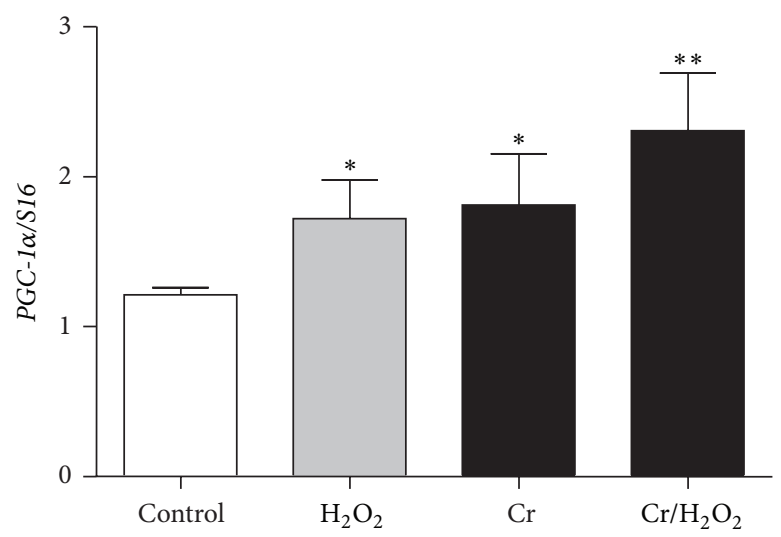

(a)

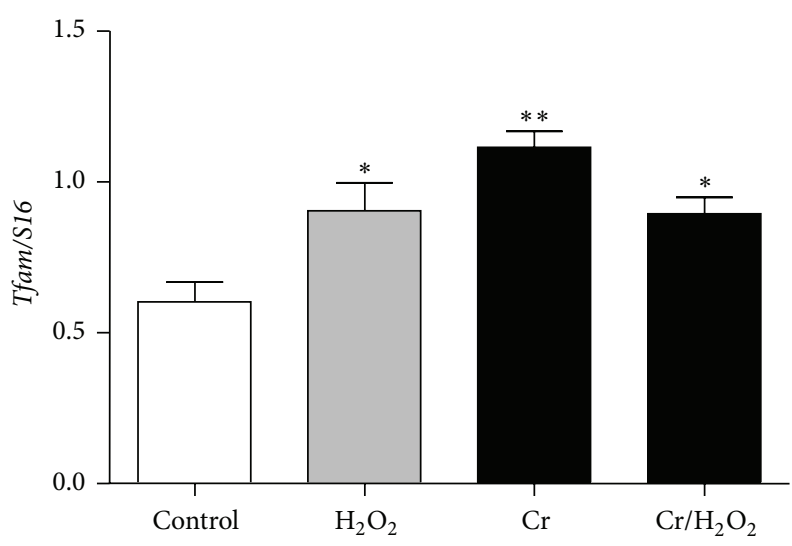

(b)

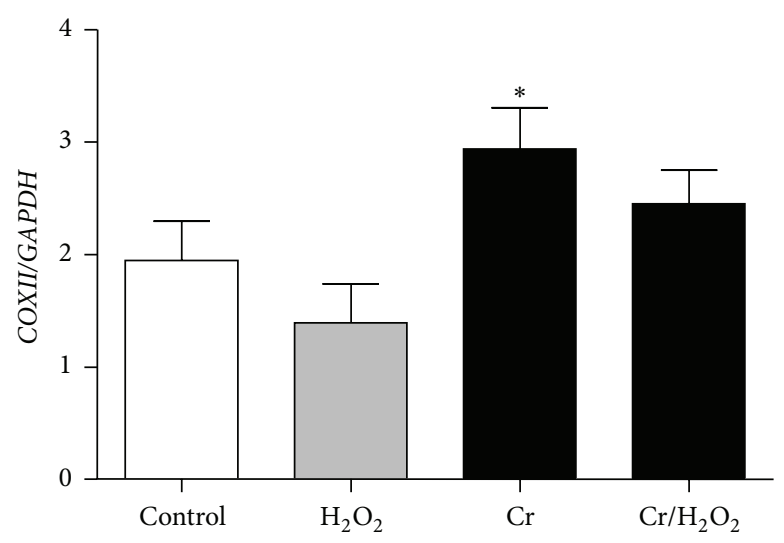

(c)

FIGURE 5: Effect of $\mathrm{Cr}$ on mitochondrial biogenesis under normal or oxidatively stressing conditions. mRNA expression level of $P G C$-1 $\alpha$ (a) and of Tfam (b) at DifD1; mtDNA content at DifD3 (c). Quantitative analysis of PGC-1 $\alpha$ and Tfam was performed by real-time PCR, and the amount of each target transcript was related to that of the reference gene (the ribosomal protein S16). The mtDNA content was determined by real-time PCR and expressed as mtDNA/nDNA ratio $(C O X I I / G A P D H)$. Data are expressed as the mean \pm SEM. ${ }^{*} P \leq 0.05 ;{ }^{* *} P \leq 0.01$ compared to control $(n=5)$.

as compared to $\mathrm{Cr}$-only- or $\mathrm{H}_{2} \mathrm{O}_{2}$-only-treated conditions, suggesting that the two agents act in a somehow additive fashion. A similar behaviour could be observed with regard to ACC phosphorylation (Figure 4). It is of note that AICAR, a reference AMPK activator, induced a robust increase of its phosphorylation in our cellular setting.

3.6. Effect of $\mathrm{Cr}$ on Mitochondrial Biogenesis and mtDNA Content. $P G C-1 \alpha$ represents a master regulator of mitochondrial biogenesis by interacting with several transcription factors also crucial for maintaining mitochondrial DNA integrity [44, 45]. Figures 5(a) and 5(b) show the transcription level of both $P G C-1 \alpha$ and Tfam, quantified using RT realtime PCR at DifD1. As shown in Figure 5(a), analysis of C2C12 cells treated with $\mathrm{H}_{2} \mathrm{O}_{2}$ or $\mathrm{H}_{2} \mathrm{O}_{2}+\mathrm{Cr}$ showed that their $P G C-1 \alpha$ expression levels were markedly increased as compared to controls. Similar to PGC-1 $\alpha$, the Tfam expression level during myoblasts differentiation was characterized by a tendency to increase (Figure 5(b)) as compared to controls. MtDNA copy number can be considered as another marker of mitochondrial biogenesis and, in general, of muscle health [46]. Our results show that, at DifD3, the relative mtDNA copy number in Cr-loaded and $\mathrm{H}_{2} \mathrm{O}_{2}$-injured cells was significantly higher as compared to $\mathrm{Cr}$-free $\mathrm{C} 2 \mathrm{C} 12$ cells exposed to $\mathrm{H}_{2} \mathrm{O}_{2}$ (Figure 5(c)).

3.7. Mitochondrial Proteomic Analysis. We next studied the mitochondrial proteome in $\mathrm{C} 2 \mathrm{C} 12$ differentiating myoblasts using a $2 \mathrm{D}$ approach described previously [33]. We found that the 2D profile of $\mathrm{H}_{2} \mathrm{O}_{2}$-injured mitochondria (Figure 6(b)) was significantly different as compared to that of controls (Figure 6(a)); in particular, a significant reduction-or even the disappearance-of several proteins could be observed, especially in the $\mathrm{pH}$ range $4-7$. By contrast, $\mathrm{Cr}$ supplementation afforded a nearly complete protection from these alterations and produced a protein pattern almost identical to control (Figure 6(c)), including the proteins whose expression significantly increases over differentiation [33]. In particular, the increased expression of dihydrolipoamide dehydrogenase (spot 4) and ATP synthase D chain (spot 7), both involved in energy production, reflects the capacity of preserving mitochondrial function. 


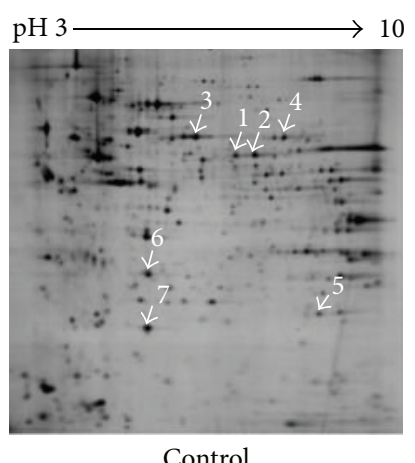

Control

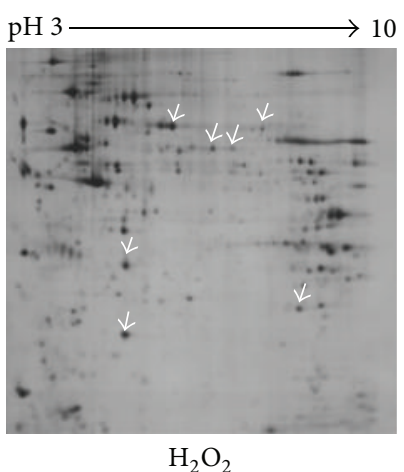

(b)

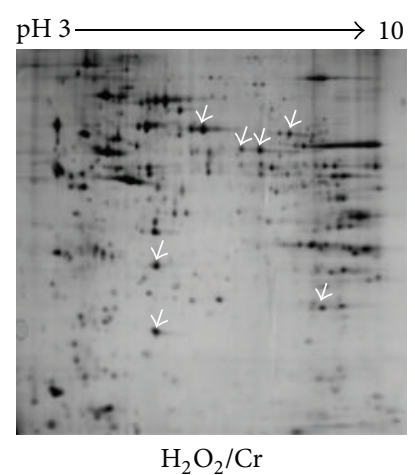

(c)

FIGURE 6: Effect of $\mathrm{Cr}$ on the mitochondrial proteomic pattern. Mitochondrial proteomic mapping from myogenic C2C12 cells at DifD3; (a) control cells; (b) $\mathrm{H}_{2} \mathrm{O}_{2}$-treated cells; and (c) Cr-supplemented myocytes treated with $\mathrm{H}_{2} \mathrm{O}_{2}$ as in (b). The arrows show differentially expressed proteins after $\mathrm{H}_{2} \mathrm{O}_{2}$ treatment. The major differences in $\mathrm{H}_{2} \mathrm{O}_{2}$-treated cells as compared to (a) and (c) were found in 1 and 2, mitochondrial aldehyde dehydrogenase-2; 3, protein disulfide isomerase; 4, dihydrolipoamide dehydrogenase; 5 , Mn superoxide dismutase; 6 , prohibitin; and 7, ATP synthase D chain. Images were representative of five independent experiments.

\section{Discussion}

In a previous study, we showed that $\mathrm{Cr}$ protects differentiating $\mathrm{C} 2 \mathrm{C} 12$ myoblasts from $\mathrm{H}_{2} \mathrm{O}_{2}$-dependent myogenic arrest [15] and that in oxidative stressing conditions, $\mathrm{Cr}$, through multiple and converging mechanisms (increased expression of myogenic factors and of IGF-1, reduction of GSH consumption and of cell death through its antioxidant activity, and amelioration and preservation of cellular energy charge through increased availability of Cr Phosphate, CrP), might provide myoblasts with an enhanced adaptive potential resulting in the preservation of myogenic capacity.

Here, we demonstrate that $\mathrm{Cr}$ effectively and invariably protects mitochondrial structure and function of differentiating myoblasts from the damage inflicted by exogenously added $\mathrm{H}_{2} \mathrm{O}_{2}(0.3 \mathrm{mM}$ for $1 \mathrm{~h}$, DifD1), providing novel insights into the cellular mechanisms of $\mathrm{Cr}$ in preventing the myogenic arrest caused by oxidative challenge.

Among the cellular targets of oxidative attack, ultrastructural TEM analysis showed and confirmed that mitochondria appear to be seriously damaged and, interestingly, $\mathrm{Cr}$ was capable of preserving their integrity. Mitochondria have been recognized as crucial players in myogenesis, and a considerable body of evidence suggests that impairment of their subcellular organisation and activity blocks myogenic differentiation $[15,26,30,47,48]$. Our data further confirm this notion and also highlight the importance of preserving mitochondrial integrity in this differentiation process.

We adopted a morphofunctional and biochemical approach to study the mitochondrial structural organisation, specific mitochondria-targeted signaling induced by $\mathrm{Cr}$, and other related functions using the $\mathrm{C} 2 \mathrm{C} 12$ myogenic cellular model.

We found that oxidative insult induced multiple damage to muscle mitochondria, such as ultrastructural loss of cristae, osmotic swelling, networking destruction, decrease in mitochondrial mass, mitochondrial impaired function $(\Delta \Psi)$, reduction of mtDNA copy number, increase in cardiolipinperoxidation, and quantitative modification of mitochondrial protein expression pattern. With regard to the fate of oxidatively damaged mitochondria, a significant proportion was irreversibly removed by lysosomal activation, an event that has been previously described [49]. Cr supplementation prevented these severe ROS-dependent injuries and alterations and preserved mitochondrial integrity, biogenesis, and function, and, notably, protection of mitochondria invariably coincided with the restoration of myoblast differentiation under oxidative stressing conditions.

In particular, confocal microscopy/image analyses showed that supplemental Cr preserved mitochondrial morphology, single unit integrity, and networking immediately after oxidative insult. Importantly, the prompt assembly of elongated mitochondrial networks is a necessary condition for mitochondrial biogenesis, and both events are critically involved in myoblast differentiation [48]. Hence, the Crmediated reduction of the mitochondrial network fragmentation reflects the efficacy of its protective potential.

The abovementioned protective effects promoted by $\mathrm{Cr}$ are likely to depend on multiple mechanisms, a notion in line with the well-established Cr pleiotropism [3, 12, 50-52]. For instance, the lower degree of $\mathrm{H}_{2} \mathrm{O}_{2}$-inflicted cardiolipin peroxidation, a marker of mitochondrial oxidative damage [53], is conceivable with the direct antioxidant capacity of Cr $[15,16]$, and indeed also Trolox reduces the extent of cardiolipin peroxidation. However, according to previous data [15], the antioxidant capacity alone is a condition which may favour cell survival but is insufficient to fully protect cells from myogenic arrest: such a conclusion can be drawn from the observation that Trolox-loaded $\mathrm{H}_{2} \mathrm{O}_{2}$-injured C2C12 cells are unable to complete the differentiation task. Thus, the effects promoted by $\mathrm{Cr}$ are more complex as compared to those of a mere bona fide antioxidant and can be explained on the basis of its established pleiotropism [3, 12, 50, 52]. 
Similarly, another central event is the Cr-related maintenance of the mitochondrial $\Delta \Psi$ (Figure 2), that is, mitochondrial function, which in turn may depend on its antioxidant effect; the contribution to an increased cellular energy charge and utilization through the larger availability of $\mathrm{CrP}$ [15]; the stabilization of mitochondrial $\mathrm{Cr}$ kinase in its active octameric form, which is known to consolidate the structure of mitochondrial membranes and increase their resistance to ROS or hypoxia $[3,54]$; and the protection of mitochondrial permeability transition pore complex [55].

The Cr-dependent preservation of mitochondrial integrity and function in oxidatively injured cells is further supported by the $2 \mathrm{D} \mathrm{mt}$-protein analysis. Mitochondria purified from oxidatively injured cells at DifD3 had a protein profile similar to that observed in mitochondria from undifferentiated myoblasts, pointing to the $\mathrm{H}_{2} \mathrm{O}_{2}$-related myogenic inhibition, while $\mathrm{Cr}$ supplementation resulted in a protein pattern highly similar to that of normally differentiating myoblasts.

In this study, we highlighted a further mechanism which may significantly contribute to the mitochondrially oriented Cr effects, namely, the activation of AMPK. AMPK is a pivotal energy sensor playing a central role in linking mitochondrial function to cellular metabolism [43, 56-59]. It is widely accepted that its pharmacological activation in resting muscle has deep effects on the expression of an array of genes related to mitochondrial biogenesis and function [60-62]. In our intoxication/protection paradigm, AMPK activation is complex since it is promoted by both $\mathrm{H}_{2} \mathrm{O}_{2}$ and $\mathrm{Cr}$. In the case of $\mathrm{H}_{2} \mathrm{O}_{2}$, it activates AMPK per se, an event that might constitute a physiological response to ROS in an attempt to counteract the differentiation arrest through the induction of an adaptive pathway promoting, for example, mitochondrial biogenesis and oxidative metabolism, both functionally oriented to better energy recovery and homeostasis (see also below). However, despite this attempt, cells undergo complete differentiation arrest, suggesting that this cellular response is per se insufficient to counteract this stress.

According to previous reports by other groups [57, 58], here we report that $\mathrm{Cr}$ per se caused increased phosphorylation of AMPK $(31 \% \pm 2.7)$. More interestingly, this increase seems to be additive to that promoted by $\mathrm{H}_{2} \mathrm{O}_{2}(25 \% \pm$ 4.71); indeed, in Cr-supplemented cells exposed to oxidative stress, AMPK phosphorylation increased by $66 \% \pm 7.10$, a condition that coincides with the recovery of a quasi-normal myogenic ability. Thus, it is conceivable that the sum of these two distinct AMPK activation instances, along with the other $\mathrm{Cr}$ benefits, is sufficient to significantly help cells to overcome the differentiative arrest imposed by $\mathrm{H}_{2} \mathrm{O}_{2}$. In other words, the increased and cumulative activation of AMPK may represent another relevant feature of $\mathrm{Cr}$-pleiotropic nature, which concurs with the rescue of the differentiation capacity. In this regard, it is worth noting that although the role of AMPK phosphorylation in the myogenic process is not yet fully understood [12, 52], Fu et al. [59] described that transient AMPK activation by AICAR resulted in myogenin increase, promoting myogenesis in $\mathrm{C} 2 \mathrm{C} 12$ cells. Incidentally, we too reported [15] an increase of myogenin upon $\mathrm{Cr}$ supplementation in the same differentiation setting as in the present study.

Moreover, here we also assessed the gene expression level of the "master" regulator of the mitochondrial biogenesis, namely, $P G C-1 \alpha$ and Tfam, regulated by $P G C-1 \alpha$, required for mitochondrial biogenesis, which mirrors the changing levels of mtDNA in the cell and plays a crucial role in mtDNA maintenance $[63,64]$. In particular, the expression level of these two transcription factors increased under all the conditions tested, as compared to controls, and may reflect a behaviour that is functionally convergent to that seen for AMPK. Hence, they may play a role in the promotion of mitochondrial biogenesis under oxidative stressing conditions and, in turn, in the restoration of the myogenic capacity. Mitochondrial DNA copy number reflects the extent of mitochondrial biogenesis, whose variations can be better appreciated at later differentiation times (i.e., DifD3). As expected, oxidative stress caused a significant reduction of mtDNA copies; Cr per se slightly increased mtDNA content according to its prodifferentiation capacity [12] and, more interestingly, prevented the drastic reduction of mtDNA caused by oxidative stress.

Data presented herein also indicate that Cr per se induces significant modifications of some parameters directly or indirectly associated with mitochondrial content and function, such as increased mtDNA copies, $\Delta \Psi$, AMPK phosphorylation, $P G C-1 \alpha$ expression, and a slight augmentation of mitochondrial mass: these effects are likely to be involved in the well known anabolic action of $\mathrm{Cr}$ in skeletal muscle [12].

\section{Conclusions}

On the whole, our results highlight that AMPK activation and $P G C-1 \alpha$ upregulation could be important for maintaining the myogenic wave and differentiation even in adverse stressing conditions such as oxidative insult. These effects could represent an important mechanism contributing to the benefits of supplemental $\mathrm{Cr}$ in those muscular diseases, where oxidative stress, mitochondrial impairment, and differentiative imbalance play a causative role, for example, muscular dystrophies, mitochondrial cytopathies, aging, disuse atrophy, and sarcopenia $[6-8,65]$.

In this study, we have identified a wide range of converging mitochondrial positive effects of $\mathrm{Cr}$ in $\mathrm{C} 2 \mathrm{C} 12$ cells differentiating under normal or oxidative stressing conditions, which contribute to $\mathrm{Cr}$ pleiotropism at the basis of its myogenic and protective activities.

Indeed, these mitochondrial effects are likely to concur with the other cellular actions that we and others have identified as important in supporting the myogenic process and protecting its execution from oxidative insult, such as the mild direct antioxidant activity $[16,50]$, ameliorated cellular energy $[15,54]$, increased expression of muscle regulatory factors and of IGF-1 [15], decreased apoptotic susceptibility, and cell death [3].

Together, these conditions jointly favour protection and rapid mitochondrial recovery minimizing the effects of oxidative damage, thus restoring myogenesis. 


\section{Competing Interests}

The authors declare that there are no competing interests.

\section{Acknowledgments}

The authors wish to thank Professor Timothy Bloom, Centro Linguistico di Ateneo of the University of Urbino Carlo Bo, for critically reading the paper and Dr. Ulrike Braun, from AlzChem, for kindly providing Creapure.

\section{References}

[1] P. L. Greenhaff, A. Casey, A. H. Short, R. Harris, K. Soderlund, and E. Hultman, "Influence of oral creatine supplementation of muscle torque during repeated bouts of maximal voluntary exercise in man," Clinical Science, vol. 84, no. 5, pp. 565-571, 1993.

[2] P. D. Balsom, K. Söderlund, B. Sjödin, and B. Ekblom, "Skeletal muscle metabolism during short duration high-intensity exercise: influence of creatine supplementation," Acta Physiologica Scandinavica, vol. 154, no. 3, pp. 303-310, 1995.

[3] T. Wallimann, M. Tokarska-Schlattner, and U. Schlattner, "The creatine kinase system and pleiotropic effects of creatine," Amino acids, vol. 40, no. 5, pp. 1271-1296, 2011.

[4] M. Tarnopolsky and J. Martin, "Creatine monohydrate increases strength in patients with neuromuscular disease," Neurology, vol. 52 , no. 4 , pp. 854-857, 1999.

[5] A. Louis, J. Lebacq, J. R. Poortmans et al., "Beneficial effects of creatine supplementation in dystrophic patients," Muscle and Nerve, vol. 27, no. 5, pp. 604-610, 2003.

[6] M. A. Tarnopolsky, "Clinical use of creatine in neuromuscular and neurometabolic disorders," Sub-Cellular Biochemistry, vol. 46, pp. 183-204, 2007.

[7] R. A. Kley, M. A. Tarnopolsky, and M. Vorgerd, "Creatine for treating muscle disorders," The Cochrane Database of Systematic Reviews, no. 6, Article ID CD004760, 2013.

[8] G. D’Antona, S. M. Nabavi, P. Micheletti et al., "Creatine, Lcarnitine, and $\omega 3$ polyunsaturated fatty acid supplementation from healthy to diseased skeletal muscle," BioMed Research International, vol. 2014, Article ID 613890, 16 pages, 2014.

[9] S. Olsen, P. Aagaard, F. Kadi et al., "Creatine supplementation augments the increase in satellite cell and myonuclei number in human skeletal muscle induced by strength training," The Journal of Physiology, vol. 573, no. 2, pp. 525-534, 2006.

[10] M. C. Devries and S. M. Phillips, "Creatine supplementation during resistance training in older adults-a meta-analysis," Medicine and Science in Sports and Exercise, vol. 46, no. 6, pp. 1194-1203, 2014.

[11] J. Kim, J. Lee, S. Kim, D. Yoon, J. Kim, and D. J. Sung, "Role of creatine supplementation in exercise-induced muscle damage: a mini review," Journal of Exercise Rehabilitation, vol. 11, no. 5, pp. 244-250, 2015.

[12] P. Sestili, E. Barbieri, and V. Stocchi, "Effects of creatine in skeletal muscle cells and in myoblasts differentiating under normal or oxidatively stressing conditions," Mini-Reviews in Medicinal Chemistry, vol. 16, no. 1, pp. 4-11, 2015.

[13] J. S. Ingwall, M. F. Morales, and F. E. Stockdale, "Creatine and the control of myosin synthesis in differentiating skeletal muscle," Proceedings of the National Academy of Sciences of the United States of America, vol. 69, no. 8, pp. 2250-2253, 1972.
[14] M. Louis, R. Van Beneden, M. Dehoux, J. P. Thissen, and M. Francaux, "Creatine increases IGF-I and myogenic regulatory factor mRNA in $\mathrm{C}_{2} \mathrm{C}_{12}$ cells," FEBS Letters, vol. 557, no. 1-3, pp. 243-247, 2004.

[15] P. Sestili, E. Barbieri, C. Martinelli et al., "Creatine supplementation prevents the inhibition of myogenic differentiation in oxidatively injured C2C12 murine myoblasts," Molecular Nutrition \& Food Research, vol. 53, no. 9, pp. 1187-1204, 2009.

[16] P. Sestili, C. Martinelli, G. Bravi et al., "Creatine supplementation affords cytoprotection in oxidatively injured cultured mammalian cells via direct antioxidant activity," Free Radical Biology \& Medicine, vol. 40, no. 5, pp. 837-849, 2006.

[17] M. Berneburg, T. Gremmel, V. Kürten et al., "Creatine supplementation normalizes mutagenesis of mitochondrial DNA as well as functional consequences," Journal of Investigative Dermatology, vol. 125, no. 2, pp. 213-220, 2005.

[18] H. Lenz, M. Schmidt, V. Welge et al., "The creatine kinase system in human skin: protective effects of creatine against oxidative and UV damage in vitro and in vivo," Journal of Investigative Dermatology, vol. 124, no. 2, pp. 443-452, 2005.

[19] C. Guidi, L. Potenza, P. Sestili et al., "Differential effect of creatine on oxidatively-injured mitochondrial and nuclear DNA," Biochimica et Biophysica Acta-General Subjects, vol. 1780, no. 1, pp. 16-26, 2008.

[20] C. F. Brunk and D. Yaffe, "The reversible inhibition of myoblast fusion by ethidium bromide (EB)," Experimental Cell Research, vol. 99, no. 2, pp. 310-318, 1976.

[21] W. Korohoda, Z. Pietrzkowski, and K. Reiss, "Chlorampheni$\mathrm{col}$, an inhibitor of mitochondrial protein synthesis, inhibits myoblast fusion and myotube differentiation," Folia Histochemica et Cytobiologica, vol. 31, no. 1, pp. 9-13, 1993.

[22] N. H. Herzberg, E. Middelkoop, M. Adorf et al., "Mitochondria in cultured human muscle cells depleted of mitochondrial DNA," European Journal of Cell Biology, vol. 61, no. 2, pp. 400408, 1993.

[23] N. H. Herzberg, R. Zwart, R. A. Wolterman et al., "Differentiation and proliferation of respiration-deficient human myoblasts," Biochimica et Biophysica Acta (BBA)-Molecular Basis of Disease, vol. 1181, no. 1, pp. 63-67, 1993.

[24] S. C. Leary, B. J. Battersby, R. G. Hansford, and C. D. Moyes, "Interactions between bioenergetics and mitochondrial biogenesis," Biochimica et Biophysica Acta-Bioenergetics, vol. 1365, no. 3, pp. 522-530, 1998.

[25] G. Biswas, O. A. Adebanjo, B. D. Freedman et al., "Retrograde $\mathrm{Ca}^{2+}$ signaling in $\mathrm{C} 2 \mathrm{C} 12$ skeletal myocytes in response to mitochondrial genetic and metabolic stress: a novel mode of inter-organelle crosstalk," The EMBO Journal, vol. 18, no. 3, pp. 522-533, 1999.

[26] P. Rochard, A. Rodier, F. Casas et al., "Mitochondrial activity is involved in the regulation of myoblast differentiation through myogenin expression and activity of myogenic factors," The Journal of Biological Chemistry, vol. 275, no. 4, pp. 2733-2744, 2000.

[27] S. C. Leary, B. C. Hill, C. N. Lyons et al., "Chronic treatment with azide in situ leads to an irreversible loss of cytochrome c oxidase activity via holoenzyme dissociation," The Journal of Biological Chemistry, vol. 277, no. 13, pp. 11321-11328, 2002.

[28] Z. Yun, Q. Lin, and A. J. Giaccia, "Adaptive myogenesis under hypoxia," Molecular and Cellular Biology, vol. 25, no. 8, pp. 3040-3055, 2005.

[29] P. Pawlikowska, B. Gajkowska, J.-F. Hocquette, and A. Orzechowski, "Not only insulin stimulates mitochondriogenesis in 
muscle cells, but mitochondria are also essential for insulinmediated myogenesis," Cell Proliferation, vol. 39, no. 2, pp. 127$145,2006$.

[30] P. Seyer, S. Grandemange, M. Busson et al., "Mitochondrial activity regulates myoblast differentiation by control of c-Myc expression," Journal of Cellular Physiology, vol. 207, no. 1, pp. 7586, 2006.

[31] N. Nakai, F. Kawano, and K. Nakata, "Mechanical stretch activates mammalian target of rapamycin and AMP-activated protein kinase pathways in skeletal muscle cells," Molecular and Cellular Biochemistry, vol. 406, pp. 1-8, 2015.

[32] P. Ferri, E. Barbieri, S. Burattini et al., "Expression and subcellular localization of myogenic regulatory factors during the differentiation of skeletal muscle C2C12 myoblasts," Journal of Cellular Biochemistry, vol. 108, no. 6, pp. 1302-1317, 2009.

[33] E. Barbieri, M. Battistelli, L. Casadei et al., "Morphofunctional and biochemical approaches for studying mitochondrial changes during myoblasts differentiation," Journal of Aging Research, vol. 2011, Article ID 845379, 16 pages, 2011.

[34] F. Luchetti, B. Canonico, E. Cesarini et al., "7-Ketocholesterol and 5,6-secosterol induce human endothelial cell dysfunction by differential mechanisms," Steroids, vol. 99, article no. 7740 , pp. 204-211, 2015.

[35] S. Salucci, S. Burattini, V. Baldassarri et al., "The peculiar apoptotic behavior of skeletal muscle cells," Histology and Histopathology, vol. 28, no. 8, pp. 1073-1087, 2013.

[36] V. Romanello, E. Guadagnin, L. Gomes et al., "Mitochondrial fission and remodelling contributes to muscle atrophy," The EMBO Journal, vol. 29, no. 10, pp. 1774-1785, 2010.

[37] F. Luchetti, B. Canonico, F. Mannello et al., "Melatonin reduces early changes in intramitochondrial cardiolipin during apoptosis in U937 cell line," Toxicology in Vitro, vol. 21, no. 2, pp. 293301, 2007.

[38] M. M. Bradford, "A rapid and sensitive method for the quantitation of microgram quantities of protein utilizing the principle of protein-dye binding," Analytical Biochemistry, vol. 72, no. 1-2, pp. 248-254, 1976.

[39] P. Sinha, J. Poland, M. Schnölzer, and T. Rabilloud, "A new silver staining apparatus and procedure for matrix-assisted laser desorption/ionization-time of flight analysis of proteins after two-dimensional electrophoresis," Proteomics, vol. 1, no. 7, pp. 835-840, 2001.

[40] A. Shevchenko, M. Wilm, O. Vorm, and M. Mann, "Mass spectrometric sequencing of proteins from silver-stained polyacrylamide gels," Analytical Chemistry, vol. 68, no. 5, pp. 850858, 1996.

[41] M. Guescini, D. Guidolin, L. Vallorani et al., "C2C12 myoblasts release micro-vesicles containing mtDNA and proteins involved in signal transduction," Experimental Cell Research, vol. 316, no. 12, pp. 1977-1984, 2010.

[42] K. Peng, Y. Tao, J. Zhang et al., "Resveratrol regulates mitochondrial biogenesis and fission/fusion to attenuate rotenone-induced neurotoxicity," Oxidative Medicine and Cellular Longevity, vol. 2016, Article ID 6705621, 12 pages, 2016.

[43] C. Handschin and B. M. Spiegelman, "Peroxisome proliferatoractivated receptor $\gamma$ coactivator 1 coactivators, energy homeostasis, and metabolism," Endocrine Reviews, vol. 27, no. 7, pp. 728-735, 2006.

[44] M. A. Parisi and D. A. Clayton, "Similarity of human mitochondrial transcription factor 1 to high mobility group proteins," Science, vol. 252, no. 5008, pp. 965-969, 1991.
[45] M. Falkenberg, M. Gaspari, A. Rantanen, A. Trifunovic, N.-G. Larsson, and C. M. Gustafsson, "Mitochondrial transcription factors B1 and B2 activate transcription of human mtDNA," Nature Genetics, vol. 31, no. 3, pp. 289-294, 2002.

[46] E. Barbieri, D. Agostini, E. Polidori et al., “The pleiotropic effect of physical exercise on mitochondrial dynamics in aging skeletal muscle," Oxidative Medicine and Cellular Longevity, vol. 2015, Article ID 917085, 15 pages, 2015.

[47] P. Seyer, S. Grandemange, P. Rochard et al., "P43-dependent mitochondrial activity regulates myoblast differentiation and slow myosin isoform expression by control of Calcineurin expression," Experimental Cell Research, vol. 317, no. 14, pp. 2059-2071, 2011.

[48] A. Wagatsuma and K. Sakuma, "Mitochondria as a potential regulator of myogenesis," The Scientific World Journal, vol. 2013, Article ID 593267, 9 pages, 2013.

[49] W.-X. Ding and X.-M. Yin, "Mitophagy: mechanisms, pathophysiological roles, and analysis," Biological Chemistry, vol. 393, no. 7, pp. 547-564, 2012.

[50] P. Sestili, C. Martinelli, E. Colombo et al., "Creatine as an antioxidant," Amino Acids, vol. 40, no. 5, pp. 1385-1396, 2011.

[51] S. Sartini, D. Lattanzi, P. Ambrogini et al., "Maternal creatine supplementation affects the morpho-functional development of hippocampal neurons in rat offspring," Neuroscience, vol. 312, pp. 120-129, 2016.

[52] P. Sestili, P. Ambrogini, E. Barbieri et al., "New insights into the trophic and cytoprotective effects of creatine in in vitro and in vivo models of cell maturation," Amino Acids, 2016.

[53] G. Paradies, G. Petrosillo, M. Pistolese, and F. M. Ruggiero, "Reactive oxygen species affect mitochondrial electron transport complex I activity through oxidative cardiolipin damage," Gene, vol. 286, no. 1, pp. 135-141, 2002.

[54] T. Wallimann, "Introduction-creatine: cheap ergogenic supplement with great potential for health and disease," SubCellular Biochemistry, vol. 46, pp. 1-16, 2007.

[55] M. Dolder, B. Walzel, O. Speer, U. Schlattner, and T. Wallimann, "Inhibition of the mitochondrial permeability transition by creatine kinase substrates. Requirement for microcompartmentation," The Journal of Biological Chemistry, vol. 278, no. 20, pp. 17760-17766, 2003.

[56] S. Jager, C. Handschin, J. St-Pierre, and B. M. Spiegelman, "AMP-activated protein kinase (AMPK) action in skeletal muscle via direct phosphorylation of PGC-1 $\alpha$," Proceedings of the National Academy of Sciences of the United States of America, vol. 104, no. 29, pp. 12017-12022, 2007.

[57] R. B. Ceddia and G. Sweeney, "Creatine supplementation increases glucose oxidation and AMPK phosphorylation and reduces lactate production in L6 rat skeletal muscle cells," The Journal of Physiology, vol. 555, no. 2, pp. 409-421, 2004.

[58] C. R. R. Alves, J. C. Ferreira, M. A. De Siqueira-Filho, C. R. Carvalho, A. H. Lancha Jr., and B. Gualano, "Creatine-induced glucose uptake in type 2 diabetes: arole for AMPK- $\alpha$ ?” Amino Acids, vol. 43, no. 4, pp. 1803-1807, 2012.

[59] X. Fu, J.-X. Zhao, M.-J. Zhu et al., "AMP-activated protein kinase $\alpha 1$ but not $\alpha 2$ catalytic subunit potentiates myogenin expression and myogenesis," Molecular and Cellular Biology, vol. 33, no. 22, pp. 4517-4525, 2013.

[60] G. R. Steinberg and B. E. Kemp, "AMPK in health and disease," Physiological Reviews, vol. 89, no. 3, pp. 1025-1078, 2009.

[61] S. Fogarty and D. G. Hardie, "Development of protein kinase activators: AMPK as a target in metabolic disorders and cancer," 
Biochimica et Biophysica Acta-Proteins and Proteomics, vol. 1804, no. 3, pp. 581-591, 2010.

[62] K. A. Coughlan, R. J. Valentine, N. B. Ruderman, and A. K. Saha, "AMPK activation: a therapeutic target for type 2 diabetes?" Diabetes, Metabolic Syndrome and Obesity: Targets and Therapy, vol. 7, pp. 241-253, 2014.

[63] M. I. Ekstrand, M. Falkenberg, A. Rantanen et al., "Mitochondrial transcription factor A regulates mtDNA copy number in mammals," Human Molecular Genetics, vol. 13, no. 9, pp. 935944, 2004.

[64] H.-C. Lee and Y.-H. Wei, "Mitochondrial biogenesis and mitochondrial DNA maintenance of mammalian cells under oxidative stress," The International Journal of Biochemistry \& Cell Biology, vol. 37, no. 4, pp. 822-834, 2005.

[65] M. A. Tarnopolsky, "Creatine as a therapeutic strategy for myopathies," Amino Acids, vol. 40, no. 5, pp. 1397-1407, 2011. 


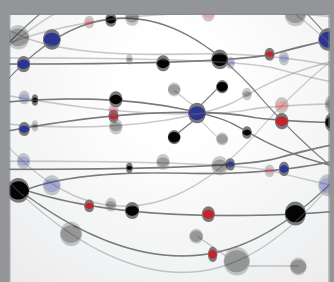

The Scientific World Journal
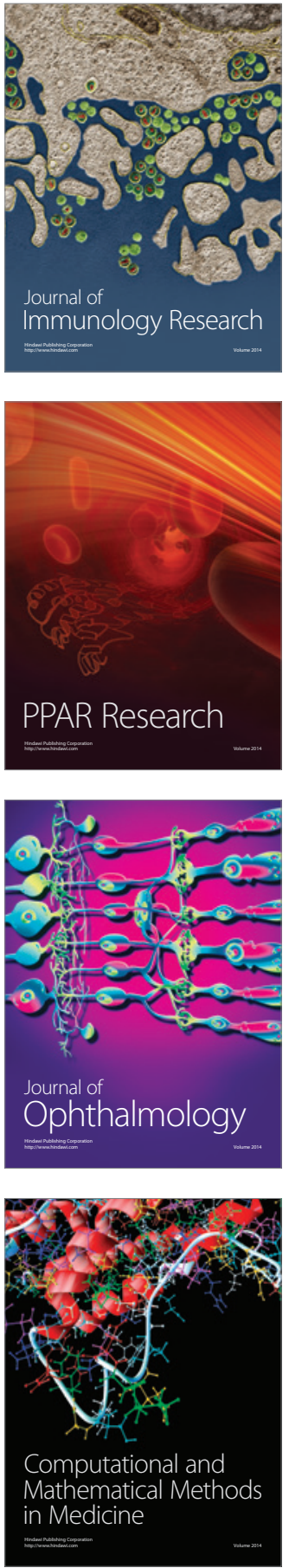

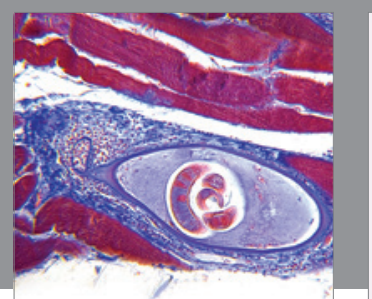

Gastroenterology Research and Practice

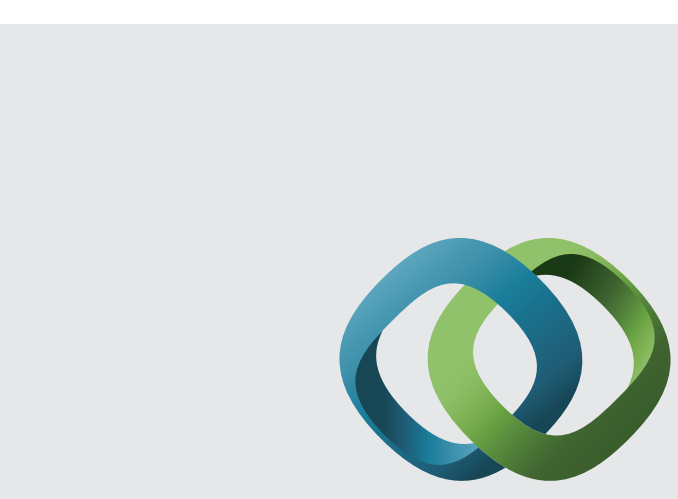

\section{Hindawi}

Submit your manuscripts at

http://www.hindawi.com
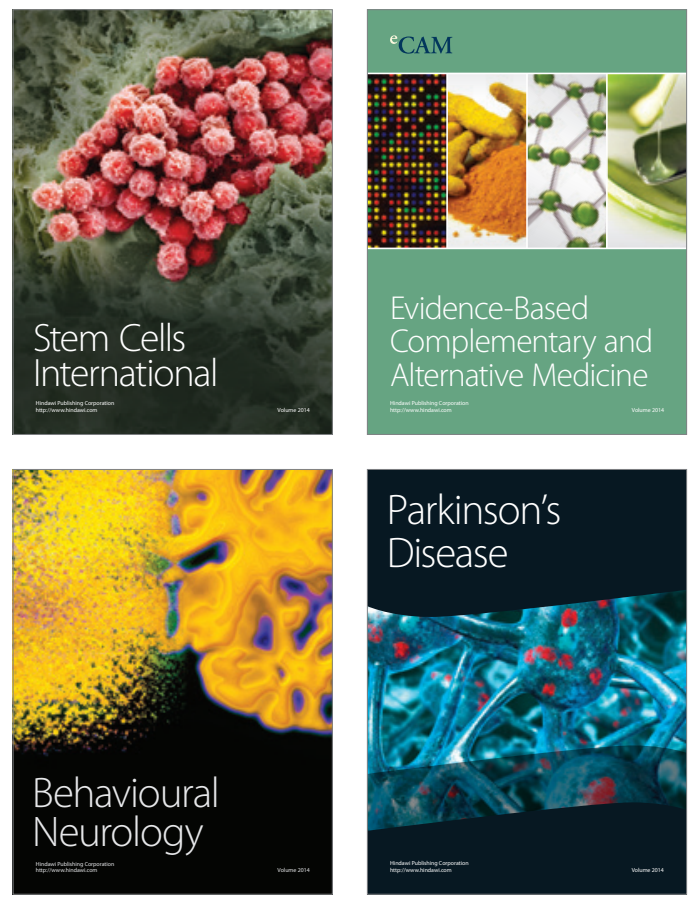
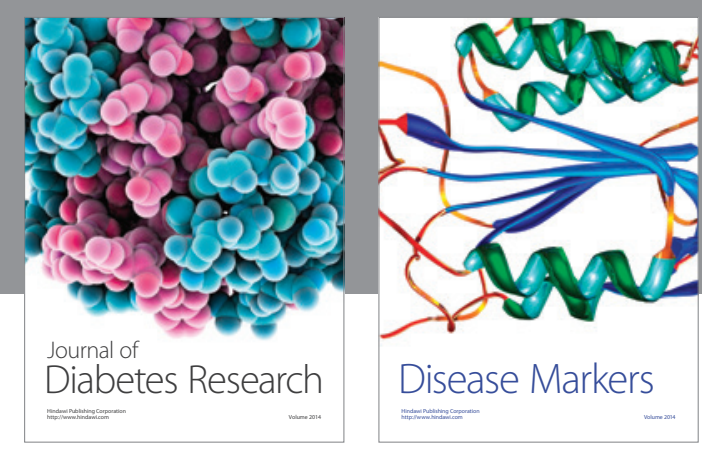

Disease Markers
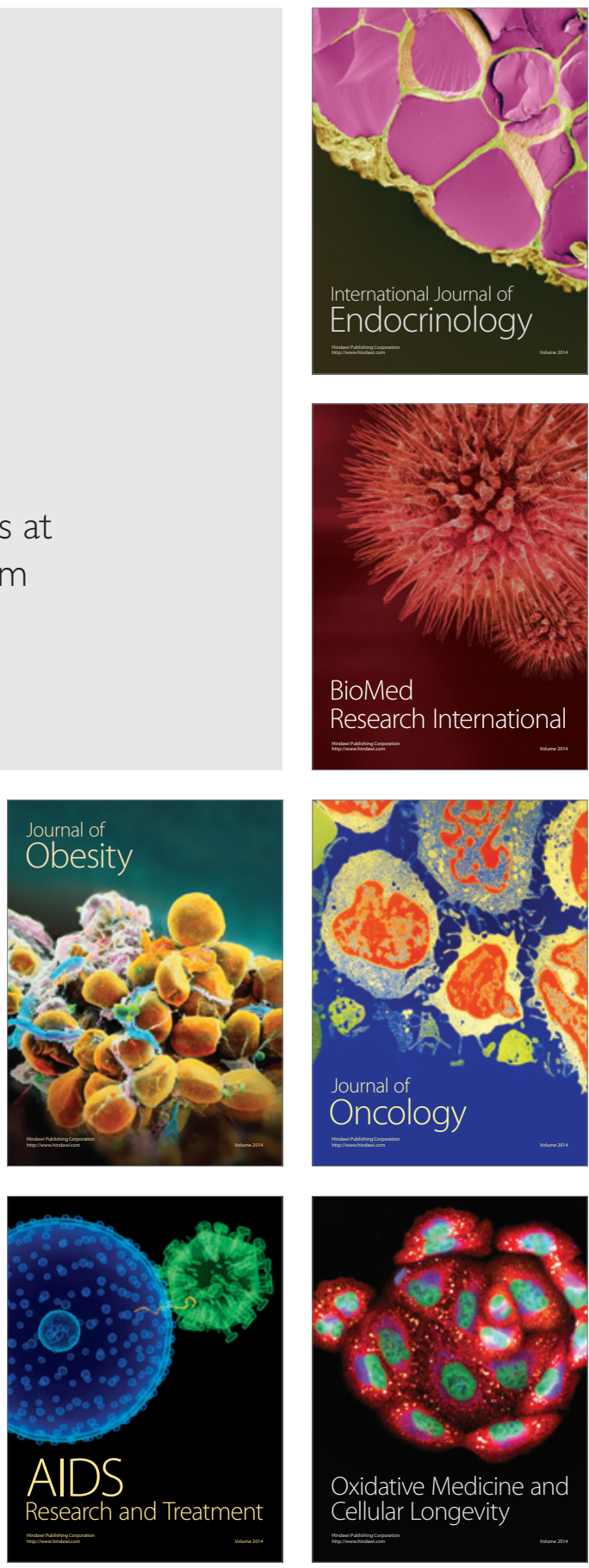